\title{
Pengembangan kWh Meter Elektronik untuk Pengecekan CT Konsumen Secara On Site
}

\author{
Fadjar Kurniadi
}

PLN UPDL Pandaan

fadjar28@gmail.com

\begin{abstract}
Current Transfomer(CT) accuracy for big customers is very important. Constraints Execution of CT accuracy testing on big customers is quite a lot of customers and scattered, and longtime outage duration. Development of electronic kwh Meter for checking on-site CT customers as a solution to these problems. The onsite CT measurement method is carried out by comparing the primary and secondary of the CT by utilizing the current coil on the electronic kWh Meter. This method has several advantages, lower costs, easy procurement, easy and fast operation, so the duration of outages can be minimized. This method is very supportive in the implementation of the Revenue Assurance program.
\end{abstract}

Keywords: Electronic Meter, CT Testing, on site

\begin{abstract}
ABSTRAK
Akurasi CT (Current Transfomer) pada pelanggan besar sangat penting. Kendala Pelaksanaan pengujian akurasi $C T$ pada pelanggan besar adalah pelanggan cukup banyak dan tersebar, dan waktu pemadaman yang lama. Pengembangan kwh Meter Alat untuk pengecekan CT Pelanggan secara on site sebagai solusi permasalahan tersebut. Metode penugukuran CT onsite dilaksanakan dengan membandingkan sisi primer dan sekunder CT dengan memanfaatkan kumparan arus pada kWh Meter elektronik. Metode ini memiliki beberapa keuntungan, antara lain biaya lebih murah, mudah pengadaan,mudah dan cepat dalam pengoperasiannya sehingga lama pemadaman dapat diminimalkan. Cara ini sangat mendukung dalam pelaksanaan program Revenue Assurance dalam memastikan kebenaran CT yang terpasang.
\end{abstract}

Kata kunci: Meter electronic, Pengecekan CT, On Site 


\section{PENDAHULUAN}

Untuk memastikan kebenaran Alat Ukur khususnya CT, maka secara periodik perlu dilakukan pemeliharaan CT dengan menguji apakah CT yang terpasang tersebut masih sesuai dengan standard atau tidak. Pada saat ini pelanggan besar yang mempergunakan CT cukup tersebar keberadaannya sehingga pengujian CT perlu dilakukan oleh unit - unit operasional PLN.

Pada saat ini dilakukan dengan melepas CT dan melakukan pengujian di laboratorium terkait. Keberadaan alat uji CT cukup terbatas. Umumnya dikota besar unit operasional PLN seperti pada UID (Unit Induk Distribusi) sebagai contoh di UID Jatim di Surabaya atau di UP3 (Unit PelaksanaPelayanan Pelanggan) yang berada di beberapa kabupaten/ kotamadya tertentu. Akurasi CT yang baik mengacu SPLN SPLN D3.014-1: 2009. Pada pelaksanaan selama ini dapat mengakibatkan pemadaman yang cukup lama.

Peralatan untuk melakukan uji juga terbatas karena harga yang cukup mahal. Pada sisi lain, jumlah pelanggan dengan CT cukup besar yang dilayani oleh unit operasional pelayanan Pelanggan yang juga tersebar dan cukup banyak.

\section{METODE/PERANCANGAN PENELITIAN}

Metode pengecekan CT, mengacu pada SPLN SPLN D3.014-1: 2009, batas kesalahan transformator arus pengukuran adalah seperti terlihat pada tabel berikut:

Tabel 1. Batas kesalahan transforator arus pengukuran

\begin{tabular}{|c|c|c|c|c|c|c|c|}
\hline \multirow{2}{*}{\multicolumn{2}{|c|}{ Parameter uji }} & \multirow{3}{*}{$\begin{array}{l}\text { Kelas } \\
\text { Akurasi } \\
0,2\end{array}$} & \multicolumn{5}{|c|}{$\%$ Arus pengenal } \\
\hline & & & 1 & 5 & 20 & 100 & 120 \\
\hline \multirow{5}{*}{$\begin{array}{l}\text { Kesalahan arus } \\
(+/-)\end{array}$} & \multirow{5}{*}[\%]{} & & - & 0.75 & 0.75 & 0.2 & 0.2 \\
\hline & & $0,2 \mathrm{~S}$ & 0.75 & 0.35 & 0.2 & 0.2 & 0.2 \\
\hline & & 0,5 & - & 1.5 & 0.75 & 0.5 & 0.5 \\
\hline & & $0,5 \mathrm{~S}$ & 1.5 & 0.75 & 0.5 & 0.5 & 0.5 \\
\hline & & 1,0 & - & 3.0 & 1.5 & 1.01 & 1.0 \\
\hline \multirow{10}{*}{$\begin{array}{l}\text { Pergeseran } \\
\text { fasa }(+/-)\end{array}$} & \multirow{5}{*}{ [menit] } & 0,2 & - & 0.75 & 0.75 & 0.2 & 0.2 \\
\hline & & $0,2 \mathrm{~S}$ & 0.75 & 0.35 & 0.2 & 0.2 & 0.2 \\
\hline & & 0,5 & - & 1.5 & 0.75 & 0.5 & 0.5 \\
\hline & & $0,5 \mathrm{~S}$ & 1.5 & 0.75 & 0.5 & 0.5 & 0.5 \\
\hline & & 1,0 & - & 3.0 & 1.5 & 1.01 & 1.0 \\
\hline & & 0,2 & - & 0.9 & 0,45 & 0,3 & 0.3 \\
\hline & & $0,2 \mathrm{~S}$ & 0.9 & 0.45 & 0.3 & 0.3 & 0.3 \\
\hline & & 0,5 & - & 2.7 & 1.35 & 0.9 & 0.9 \\
\hline & & $0,5 \mathrm{~S}$ & 2.7 & 1.35 & 0.9 & 0.9 & 0.9 \\
\hline & & 1,0 & - & 5.4 & 2.7 & 1.8 & 1.8 \\
\hline
\end{tabular}

Pemakaian meter elektronik untuk melihat akurasi CT dilakukan dengan memanfaatan salah satu fasa (missal Fasa R) untuk sisi primer CTdan fasa yang lain (misalkan T) untuk sisi sekunder sebagai berikut: 


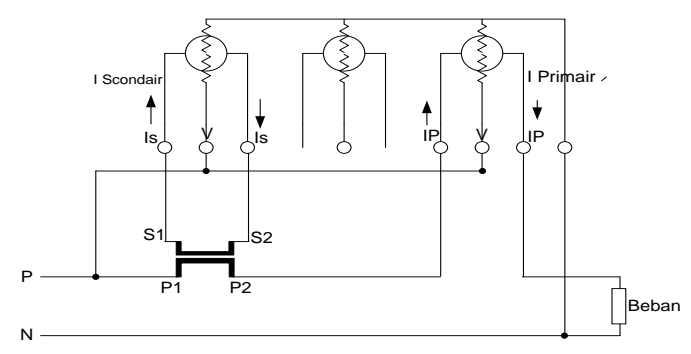

Gambar 1. Wiring diagram kWh Meter

Dari gambar 1, untuk pengukuran CT sisi primer dengan memanfaatkan kumparan arus meter elektronik fasa $\mathrm{T}$, dan untuk CT sisi sekunder dengan memanfaatkan kumparan arus meter elektronik fasa $\mathrm{R}$ dengan membentuk rangkaian tertutup seperti pada gambar diatas.

Untuk implementasi dilapangan agar pelaksanaan cepat, mudah dan murah, maka sebagai sumber arus dipergunakan auto trafo dengan rangkaian lengkap sebagai berikut:

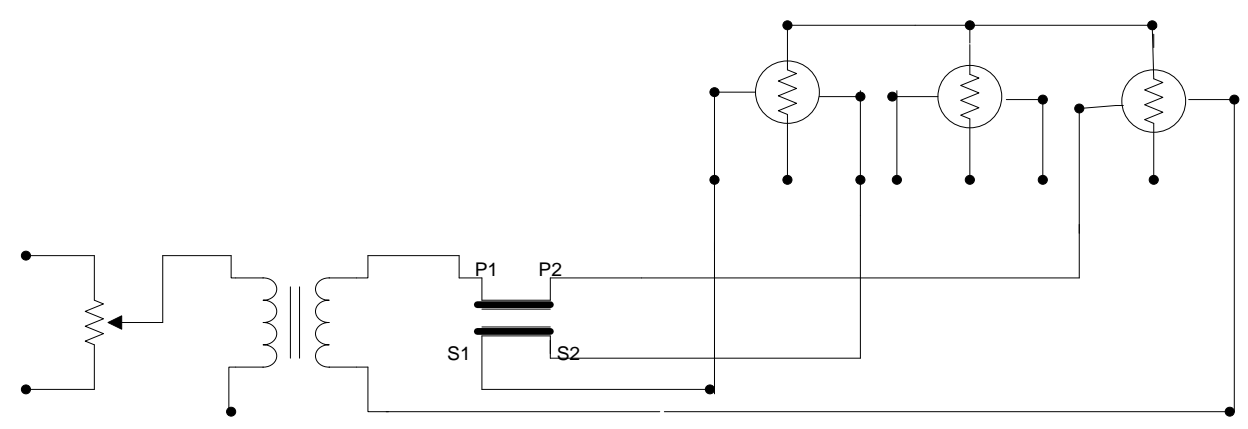

Gambar 2. Rangkaian lengkap wiring diagram peralatan

Dari gambar2, rangkaian diawali dengen pemanfaatan Autotransformator sebagai sumber arus untuk CT dan terpasang pada sisi primer CT yang akan ditest. Sisi primer dan sekunder CT dihubungkan dengan meter elektronik dengan memanfaatkan kumparan arus fasa $T$ dan fasa $R$ dengan membentuk rangkaian arus tertutup.

Implementasi pelaksanaan dilakukan dengan mempergunakan kwh meter elektronik ya perlahan menaikkan tegangan sampai didapat nilai Arus primer sesuai dengan nominal CT. Selanjutnya melihat sudut fasa yang ada dan perbandingan Ratio primer dan sekunder dari tampilan di kWh meter elektronik. Hasil yang didapat dibandingkan dengan standar CT yang normal sesuai dengan SPLN D3.014-1: 2009 pada table 1 diatas.

\section{HASIL DAN PEMBAHASAN}

Hasil Dari wiring diagram tersebut, maka dirangkai peralatan yang ada (Auto trafo, $\mathrm{kWh}$ Meter dan terminal menuju ke CT). Rating kWh Meter dipilih yang mempunya rating arus yg besar (minimal 50 A) sehingga lebih flexible pemanfaatannya. Rangkaiannya adalah seperti gambar berikut: 


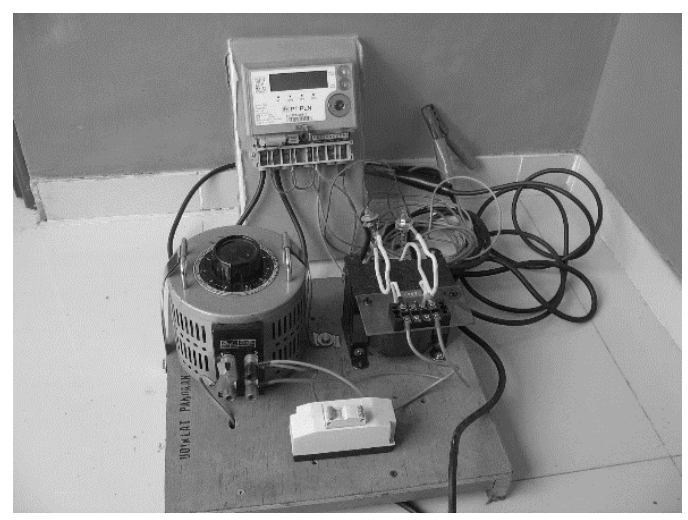

Gambar 3. Rangkaian lengkap

Dari gambar 3, terlihat rangkaian lengkap peralatan yang cukup sederhana dan mudah untuk dilakukan wiring dengan peralatan yang banyak dijumpai di unit operasional PLN meskipun pada level unit kecil. (MCB, meter elektronik, auto trafo dan kabel)

Hasil ouput pembacaan di meter elektronik yang dapat terbaca di komputer dari download sebagai berikut:
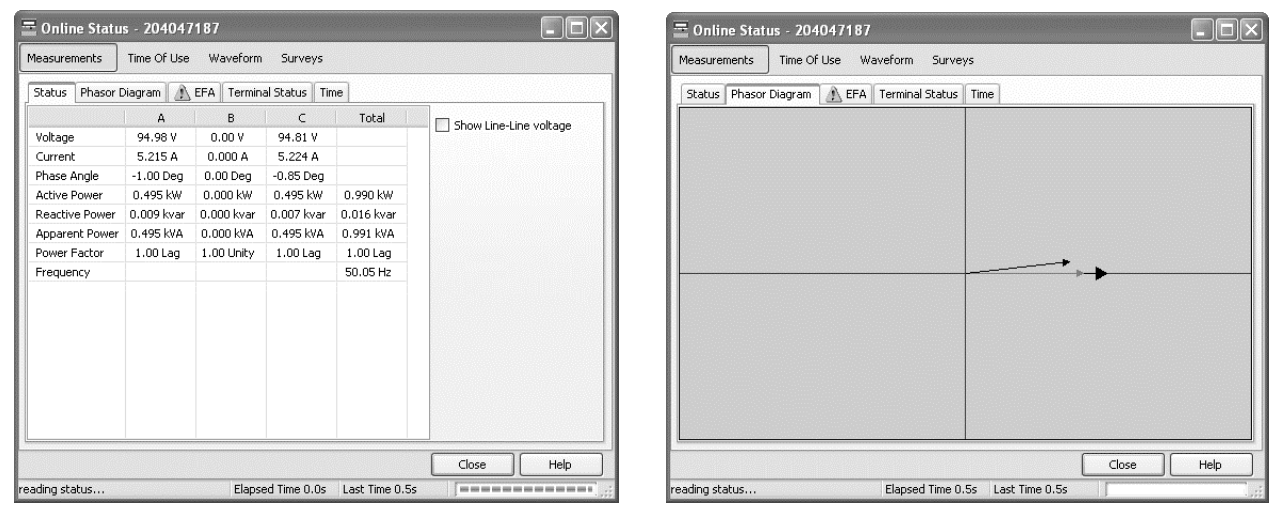

Gambar 4. Tampilan kWh Meter

Dari gambar 4, pembacaan kWh meter elektronik tersebut, semua variable yang diperlukan (Arus Primer, Arus Sekunder, dan sudut fasa) dapat diperoleh diperoleh. Ratio arus dengan $\mathrm{m}$ embandingkan status arus primer (status Current C) dengan arus sekunder (status Current A). Pergeseran fasa antara sisi primer dan sekunder, ditunjukkan pada status phase angle dan juga gambar phasor diagramnya.

Untuk menentukan CT sesuai kelas akurasinya dapat dinyatakan akurat / baik, bilamana nilai kesalahan arus dan pergeseran fasanya masih dibawah nilai yang ditetapkan sesuai table 1 diatas.

Sebagai perbandingan metode standard dan metode pemanfaatan $\mathrm{kWh}$ meter elektronik tampak seperti pada tabel berikut: 
Tabel 2. Perbandingan metode existing dan $\mathrm{kWh}$ meter elektronik

\begin{tabular}{|l|l|l|}
\hline \multicolumn{1}{|c|}{ Keterangan } & \multicolumn{1}{|c|}{ Metode Existing } & \multicolumn{1}{c|}{$\begin{array}{c}\text { Metode dg kWh Meter } \\
\text { elektronik }\end{array}$} \\
\hline Lama waktu pelaksanaan & $6-12$ jam (perlu bawa CT ke Lab) & $\begin{array}{l}\text { menit (onsite) dan } \\
\text { tanpa perlu } \\
\text { memungkinkan } \\
\text { melepas CT dari busbarnya }\end{array}$ \\
\hline Biaya peralatan & Diatas 100 juta (perlu alat test CT) & Dibawah 20 juta \\
\hline Pengadaan peralatan & $\begin{array}{l}\text { Sulit, perlu proses panitia } \\
\text { pengadaan dan import peralatan } \\
\text { dengan waktu pengadaan }>10 \text { hari }\end{array}$ & $\begin{array}{l}\text { Mudah, dapat dilakukan dengan } \\
\text { pembelian langsung atau } \\
\text { pemanfaatan meter diGudang / } \\
\text { existing dan produk local dengan } \\
\text { waktu pengadaan < 7 hari }\end{array}$ \\
\hline Metode pelaksanaan & Sulit (perlu melepas CT) & $\begin{array}{l}\text { Mudah (tanpa melepas CT dan } \\
\text { secara onsite) }\end{array}$ \\
\hline
\end{tabular}

Jumlah pelanggan PLN yang memakai CT lebih dari 100.000 pelanggan dan memberikan kontribusi diatas $40 \%$ yang tersebar di sekitar 500 Unit Layanan pelanggan di perkotaan dan pedesaaan.

\section{KESIMPULAN DAN SARAN}

Metode pemanfaatan kWh meter elektronik untuk mengetahui akurasi CT dapat dilakukan secara onsite. Metode ini lebih murah (10 - $20 \%$ dari biaya existing), mudah (tanpa perlu melepas CT tetapi dilakukan onsite dan meminimalkan waktu pelaksanaan dan pemadaman (+/- 12,5\%).

\section{UCAPAN TERIMAKASIH}

Penulis mengucapkan terima kasih kepada PLN UPDL Pandaan, UP3 Malang, ULP Pandaan dan ULP Sukorejo UP3 Pasuruan untuk support dan persetujuan implementasi test CT dilokasi pelanggan secara on site dan STT PLN atas support dan penyempurnaan penulisannya.

\section{DAFTAR PUSTAKA}

[1] PT. PLN (Persero), 2009 SPLN D3.014-1: Trafo Instrument Untuk Sistem Distribusi (Trafo Arus), Jakarta PT PLN (Persero)

[2] PT. PLN (Persero), 2010 SPLN D3.006-1: Meter static energy listrik phasa tiga, Jakarta PT PLN (Persero)

[3] PT. PLN (Persero), 2012, SPLN D3.015-2. Alat Pengukur, Pembatas Dan Perlengkapannya (APP TR Pengukuran Tidak Langsung Fasa Tiga untuk Pelanggan 53 kVA s/d 197 kVA. Jakarta PT PLN (Persero) [1] PT. PLN (Persero), 2010 Buku 1: Kriteria Disain Enjinering Konstruksi Jaringan Disribusi Tenaga Listrik. Jakarta, PT. PLN (Persero).

[4] PT. PLN (Persero). 2010 Buku 4: Standar Konstruksi Gardu Distribusi dan Gardu Hubung Tenaga Listrik. Jakarta, PT. PLN (Persero)

[5] PT. PLN (Persero) 2014, Buku Pedoman Pemeliharaan Trafo Arus, Jakarta, PT. PLN (Persero)

[6] Sarimun, Wahyudi, 2014, Buku Saku Pelayanan Teknik Edisi Ketiga. Depok: Garamond

[7] Kadir, Abdul. 2006. Distribusi dan Utilisasi Tenaga Listrik. Jakarta : Universitas Indonesia.

[8] Sapiie, Soedjana dan Osamu Nishino. 2005. Pengukuran dan Alat - Alat Ukur Listrik. Jakarta : PT. Prandnya Paramita. 
[9] Zhao Yanping, Gao wei, Wang Jianwei,Duan Xinghu, 2017, Design and Implementation of the CT Analyzer on the Basis of the Low Pressure Test Principle, ScienceDirect

[10] Poernomo. 1979. Seri Pelajaran Teknologi secara Bergambar: Listrik. Jakarta: Bharata Karya Aksara. 